\title{
QUANTIFICAÇÃO DE COLIFORMES, Staphylococcus aureus E MESÓFILOS PRESENTES EM DIFERENTES ETAPAS DA PRODUÇÃO DE QUEIJO FRESCAL DE LEITE DE CABRA EM LATICÍNIOS ${ }^{1}$
}

\author{
Simone Ulrich PICOLI ${ }^{2}$, Marjo Cado BESSA ${ }^{3}$, Sandra Maria Ferraz CASTAGNA ${ }^{4}$, \\ Carina Philomena Tebich GOTTARDI ${ }^{3}$, Verônica SCHMIDT ${ }^{3}$, Marisa CARDOSO $^{3, *}$
}

\section{RESUMO}

O objetivo do presente estudo foi acompanhar a produção de queijo frescal de leite de cabra, avaliando a qualidade higiênica do processamento pela quantificação de coliformes, S. aureus e mesófilos totais. A produção de três diferentes lotes de queijo foi acompanhada, sendo coletadas amostras de várias etapas do processamento. Além disso, amostras de queijo pertencente ao lote acompanhado foram coletadas na prateleira de um estabelecimento comercial durante seu período de validade. Os suabes coletados foram semeados em ágar sangue ovino; as amostras de água foram submetidas à Colimetria; as demais amostras foram submetidas à contagem de S. aureus, coliformes e mesófilos totais por meio de protocolos de rotina. Verificou-se que, apesar da pasteurização ter diminuído consideravelmente as populações microbianas presentes no leite cru, a falta de sanificação adequada de um equipamento que entrava em contato com o leite cru e que dá acesso ao tanque de coagulação, resultou na recontaminação da matéria-prima. Ao final do processamento, o queijo encontrava-se dentro dos padrões exigidos pela legislação, contudo a elevada contagem de mesófilos totais sugere que sejam melhoradas as medidas de sanitização durante o processamento, a fim de garantir a qualidade higiênica e uma maior vida de prateleira ao queijo produzido.

Palavras-chave: queijo frescal, Colimetria, qualidade higiênico-sanitária, coliformes termotolerantes, tempo de prateleira.

\section{SUMMARY}

ENUMERATION OF COLIFORMS, Staphylococcus aureus AND AEROBIC MESOFILIC BACTERIA THROUGHOUT THE MANUFACTURE PROCESS OF A GOAT UNRIPENED CHEESE PRODUCED IN A DAIRY PLANT. The aim of this study was to evaluate the hygienic conditions throughout the manufacture process of a goat unripened cheese, using the enumeration of coliforms, S. aureus and aerobic mesofilic bacteria as indicators. The production of three different lots of cheese was followed, being collected samples throughout the processing steps. Furthermore, samples of cheese belonging to the same sampled lot were collected in the shelf of a commercial establishment throughout the shelf life period. Swabs were streaked onto blood agar plates; water samples were submitted to colimetric assays; all other samples were submitted to coliform, S. aureus and aerobic mesofilic bacteria enumeration using routine protocols. It was observed a great decreasing of bacterial counts in the raw milk during the pasteurization process. In spite of that, the transfer of the pasteurized milk to the coagulation tank by an equipment, which was previously in contact with the raw milk and was inadequately disinfected, resulted in the recontamination of the pasteurized milk. The packed cheese had bacterial counts according to the standards imposed by the Brazilian food regulatory agency. However, the high aerobic mesofilic bacteria counts suggest that the good manufactures practices have to be improved in order to guarantee the hygienic quality and an extender shelf life for the cheese.

Keywords: cheese, colimetric assays, hygienic quality, thermotolerant coliforms, shelf life.

\section{1 - INTRODUÇÃO}

O consumo de leite caprino e de seus derivados vem crescendo nos últimos tempos, o que tem sido relacionado à sua alta digestibilidade e à possibilidade de ser administrado a indivíduos com intolerância ao leite bovino [19].

\footnotetext{
${ }^{1}$ Recebido para publicação em 13/10/2004. Aceito para publicação em 23/1/2006 (001418)

${ }^{2}$ Instituto das Ciências da Saúde. Centro Universitário Feevale. Novo Hamburgo (RS)

${ }^{3}$ Departamento de Medicina Veterinária Preventiva, Faculdade de Veterinária da Universidade Federal do Rio Grande do Sul (UFRGS)

${ }^{4}$ Centro de Ciências Agroveterinárias. Universidade do Estado de Santa Catarina (Udesc)

Avenida Bento Gonçalves, 9.090

CEP 90450-000 - Porto Alegre (RS)

E-mail: mcardoso@vortex.ufrgs.br

*A quem a correspondência deve ser enviada
}

A obtenção higiênica do leite é o primeiro ponto crítico no processo de fabricação de queijos e de outros derivados, uma vez que o animal, os equipamentos e o ambiente da ordenha podem representar uma fonte importante de contaminação por microorganismos [14, 20]. Apesar de a pasteurização causar uma diminuição na população de microorganismos presentes no leite, algumas toxinas, como a enterotoxina estafilocócica não são inativadas, podendo causar intoxicações alimentares no consumidor [9]. Ao lado disto, a recontaminação durante o processamento pode ser um fator importante na qualidade final do produto, principalmente naquele tipo frescal, nos quais não existe uma etapa de maturação [9]. Dessa forma, as boas práticas de fabricação e as medidas de sanificação durante o processamento são cruciais para a garantia de um produto de qualidade.

Observa-se um crescente interesse entre os consumidores por produtos denominados ecológicos, por serem 
obtidos sem a presença de fármacos, pesticidas ou outras substâncias químicas. Nesse caso, a utilização de sanificantes na linha de produção não tem sido adotada, o que pode dificultar a obtenção de produtos com baixas contagens de microorganismos.

A partir disso, o objetivo do presente trabalho foi monitorar as contagens de microorganismos durante a produção de queijo frescal de leite de cabra, em um laticínio que obedece às exigências do segmento de mercado ecológico de Porto Alegre.

\section{2 - MATERIAL E MÉTODOS}

\section{1 - Coleta das amostras}

Foram realizadas três visitas mensais durante o verão (2000/2001), em um laticínio, na Grande Porto Alegre - Brasil, que produz queijo frescal de leite de cabra sob Inspeção Estadual. O referido laticínio recebia, duas vezes por semana, leite proveniente de pequenos produtores associados a uma cooperativa da região. Após análise de temperatura, densidade e acidez do leite na plataforma de recepção, a matéria-prima, em condição para o processamento, seguia o fluxograma descrito na Figura 1. O estabelecimento contava com dois funcionários responsáveis pela produção média mensal de $150 \mathrm{~kg}$ de queijo.

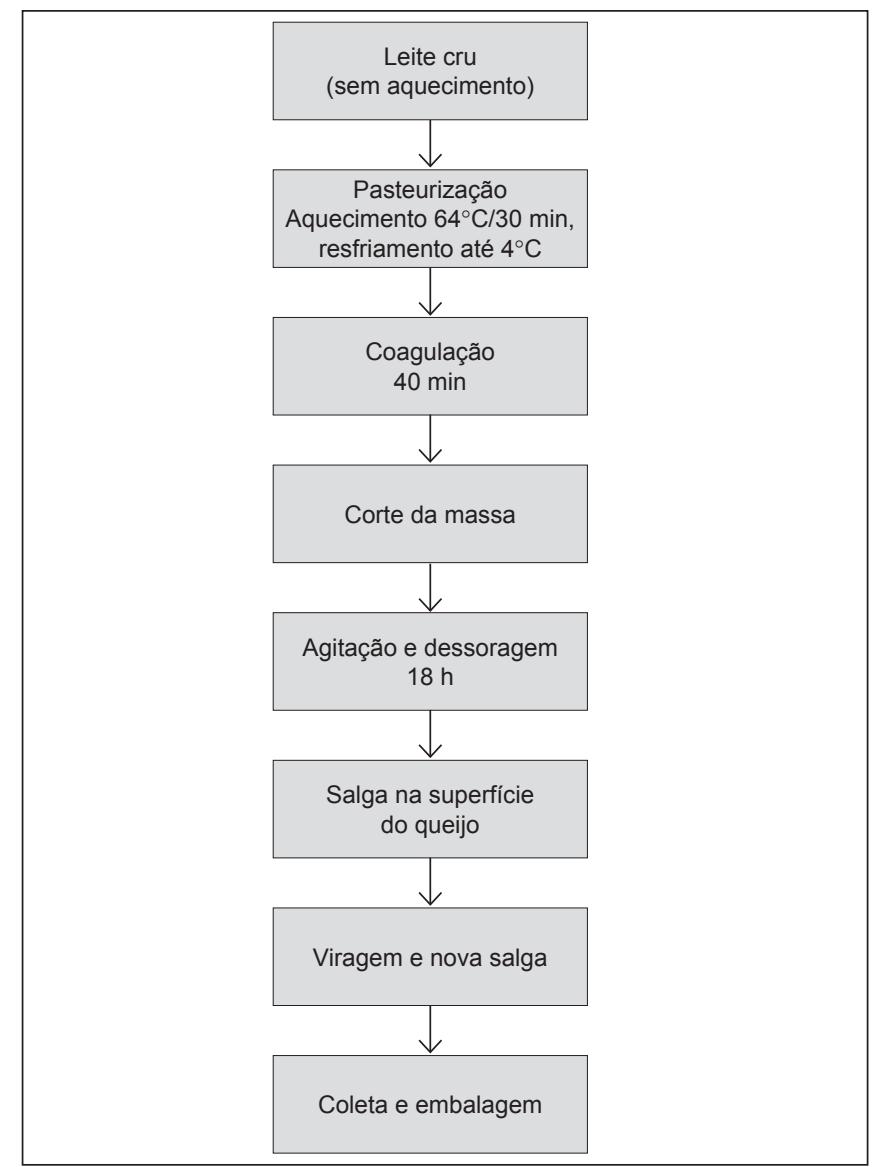

FIGURA 1 - Fluxograma de produção do queijo frescal de leite de cabra de um laticínio localizado no Rio Grande do Sul
Em cada visita, foram coletados suabes da superfície das mãos e fossas nasais dos manipuladores. Da mesma forma, foi amostrada a superfície dos equipamentos (equivalente a uma área de $10 \mathrm{~cm}^{2}$ ), utilizando suabes embebidos em água peptonada 0,1\% suplementada com $0,5 \%$ de tiossulfato de sódio. Em diferentes pontos da linha de processamento (leite na plataforma de recepção, leite na saída do pasteurizador, leite no tanque de coagulação, coalhada, massa enformada na câmara fria e queijo embalado), foram coletadas alíquotas de aproximadamente $100 \mathrm{~g}$. Foram amostrados, ainda, fermento, coalho e salmoura. Além disso, foram coletadas, ao longo do período das visitas, cinco amostras da água utilizada na limpeza dos equipamentos empregados na fabricação do queijo.

Posteriormente, do lote correspondente a esse dia de produção, coletou-se, semanalmente, uma peça de queijo exposto no balcão frigorífico em um mesmo ponto de venda ao consumidor, durante todo o período de validade do produto.

Todas as amostras foram acondicionadas em frascos estéreis e encaminhadas sob refrigeração ao setor de Medicina Veterinária da UFRGS. Os suabes coletados foram colocados em meio de transporte (Stuart) e igualmente refrigerados até sua análise.

\section{2 - Processamento das amostras}

Os suabes foram semeados em placas com ágar nutriente acrescido de $5 \%$ de sangue ovino. Após incubação a $37^{\circ} \mathrm{C}$ por $24 \mathrm{~h}$; realizou-se a identificação dos microorganismos, conforme descrito [17].

As amostras de leite e queijo foram processadas segundo SILVA; JUNQUEIRA; SILVEIRA [21], sendo que as amostras líquidas foram diluídas diretamente em água peptonada $0,1 \%$ até $10^{-6}$. As amostras sólidas foram pesadas, acrescidas (1:10) de água peptonada 0,1\% e homogeneizadas em Stomacher antes da realização das diluições seriadas. As amostras de água foram processadas de acordo com o protocolo da normatização técnica L5.202 [2].

\section{3 - Contagem de Staphylococcus aureus}

A contagem de $S$. aureus foi realizada em ágar Baird Parker (BP) [21] utilizando-se diluições de $10^{-1}$ a $10^{-6}$, contando-se, posteriormente, colônias típicas e atípicas. Para a confirmação de $S$. aureus selecionaram-se cinco colônias típicas de cada placa para teste da coagulase em tubo e, havendo menos do que cinco, testaram-se todas. Para as placas que apresentaram colônias típicas e atípicas, foram selecionadas cinco de cada tipo.

\section{4 - Contagem de coliformes totais e termotolerantes}

A contagem de coliformes totais foi realizada em ágar vermelho violeta bile (VRB, Merck) [21]. A confirmação de 
coliformes termotolerantes foi feita em caldo EC (Difco), semeando-se cinco colônias típicas. Os tubos inoculados foram incubados $\left(44,5^{\circ} \mathrm{C} / 48 \mathrm{~h}\right)$ em banho-maria sob agitação ( $68 \mathrm{rpm} / \mathrm{min}$ ), sendo considerados positivos aqueles em que houve formação de gás.

\section{5 - Contagem de mesófilos totais}

A contagem de mesófilos totais foi feita em duplicata em ágar para Contagem (PCA, Oxoid). Após a incubação $\left(37^{\circ} \mathrm{C} / 24-48 \mathrm{~h}\right)$, realizou-se a contagem das colônias presentes [21].

\section{6 - Cálculo das Unidades Formadoras de Colônia}

A média das contagens de colônias nos meios utilizados, multiplicada pelo inverso da diluição, resultou no número de Unidades Formadoras de Colônia (UFC) por $\mathrm{mL}$ ou g do produto.

\section{3 - RESULTADOS E DISCUSSÃO}

O leite e derivados oferecem aos microorganismos todas as condições necessárias à multiplicação, tornandoos um potencial veiculador de bactérias patogênicas [13]. Surtos relacionados ao consumo de queijo contaminado com bactérias causadoras de doenças transmitidas por alimentos têm sido freqüentemente relatados [24]. Existem diversas etapas, ao longo do processamento de queijos, em que os microorganismos podem ser introduzidos no produto. Desta forma, a qualidade do produto final é influenciada pelas condições higiênico-sanitárias em que o leite foi obtido, pelo processamento na indústria, pelas condições de sanificação do ambiente, qualidade da água e pelo armazenamento e transporte da matériaprima e do produto [12].
No presente estudo, avaliou-se a população de coliformes, mesófilos aeróbios e $S$. aureus presentes na matéria-prima e em ingredientes utilizados nas diversas etapas da produção de três lotes de queijo de leite de cabra, visando estabelecer possíveis pontos críticos para a introdução, multiplicação ou sobrevivência de microorganismos potencialmente patogênicos para os consumidores do produto.

Entre os microorganismos que comprometem a qualidade sanitária dos produtos de origem láctea, o S. aureus e os coliformes podem ser destacados. Os primeiros são importantes devido à possibilidade de produção de toxinas no alimento, podendo levar a toxiinfecção alimentar, enquanto que os coliformes termotolerantes são indicadores de contaminação fecal do produto e, portanto, do risco de transmissão de patógenos presentes nas fezes [8].

Apesar de outros autores [7] terem relatado a presença de coliformes fecais em amostras de queijo de leite de cabra, na ordem de até $2,4 \times 10^{6} \mathrm{UFC} / \mathrm{g}$, no presente estudo, foi constatada a ausência de coliformes termotolerantes durante todas as etapas do processamento, indicando que houve a observância de práticas higiênicas de manufatura.

A pesquisa de $S$. aureus no leite cru indicou que a quantidade média do microorganismo presente na matéria-prima foi de $8,47 \times 10^{3} \mathrm{UFC} / \mathrm{mL}$ (Tabela 1 ). Este valor esteve dentro de níveis considerados seguros quanto à produção de enterotoxinas, uma vez que contagens a partir de $10^{5}$ microorganismos $/ \mathrm{mL}$ ou g são consideradas necessárias para que haja a produção da toxina [5].

Entretanto, observa-se que as contagens de colônias típicas e atípicas no ágar Baird-Parker estiveram dentro dos limites considerados de risco. Uma grande parcela de colônias típicas e atípicas é constituída por espécies de Staphylococcus classificados como coagulase-negativos (SCN), os quais também podem ser capazes de produzir

TABELA 1 - Contagens de mesófilos, coliformes totais, colônias típicas e atípicas em ágar Baird-Parker e Staphylococcus aureus presentes em diferentes equipamentos, ingredientes e etapas de produção de queijo tipo frescal de leite de cabra em um laticínio da Grande Porto Alegre (RS)

\begin{tabular}{|c|c|c|c|c|c|c|c|c|c|c|}
\hline \multirow{2}{*}{$\begin{array}{l}\text { Microorganismo } \\
\text { (UFC/g) }\end{array}$} & \multirow[b]{2}{*}{ Lote } & \multicolumn{9}{|c|}{ Amostra coletada } \\
\hline & & Leite cru & $\begin{array}{l}\text { Leite } \\
\text { pasteurizado }\end{array}$ & $\begin{array}{l}\text { Leite no tanque } \\
\text { de coagulação }\end{array}$ & Coalhada & $\begin{array}{c}\text { Massa } \\
\text { enformada }\end{array}$ & $\begin{array}{c}\text { Queijo } \\
\text { embalado }\end{array}$ & Fermento & Coalho & Salmoura \\
\hline \multirow{3}{*}{ Mesófilos } & 1 & $3,9 \times 10^{6}$ & ND & $4,70 \times 10^{4}$ & $3,2 \times 10^{4}$ & $1,7 \times 10^{6}$ & $1,6 \times 10^{6}$ & $5,1 \times 104$ & $2,2 \times 105$ & $1,7 \times 10^{3}$ \\
\hline & 2 & $1,6 \times 10^{8}$ & $2,2 \times 10^{3}$ & $1,2 \times 10^{5}$ & $1,4 \times 10^{5}$ & $7 \times 10^{5}$ & $3,2 \times 10^{6}$ & $3,9 \times 102$ & $2,2 \times 104$ & $1,8 \times 10^{4}$ \\
\hline & 3 & $7,7 \times 10^{7}$ & $1,2 \times 10^{4}$ & $1,9 \times 10^{5}$ & $1,4 \times 10^{6}$ & $6,1 \times 10^{5}$ & $7,5 \times 10^{5}$ & $4,3 \times 102$ & $7,6 \times 103$ & $1,9 \times 10^{3}$ \\
\hline \multirow{3}{*}{ Coliformes Totais } & 1 & $2,6 \times 10^{5}$ & ND & $2 \times 10^{4}$ & $3 \times 10^{4}$ & $3 \times 10^{5}$ & $3 \times 10^{5}$ & Neg. & $2,8 \times 105$ & Neg \\
\hline & 2 & $2,6 \times 10^{5}$ & Neg. & $2 \times 10^{4}$ & $3 \times 10^{4}$ & $3 \times 10^{5}$ & $3 \times 10^{5}$ & Neg. & $2,8 \times 105$ & Neg. \\
\hline & 3 & $1,5 \times 10^{7}$ & Neg. & $1,5 \times 10^{3}$ & $4 \times 10^{4}$ & $1,4 \times 10^{5}$ & $6,5 \times 10^{4}$ & Neg. & Neg. & Neg. \\
\hline \multirow{3}{*}{$\begin{array}{l}\text { BP-Colônias } \\
\text { típicas }\end{array}$} & 1 & $9,6 \times 10^{3}$ & ND & Neg. & Neg. & $2 \times 10^{2}$ & $2 \times 10^{2}$ & Neg. & Neg. & Neg. \\
\hline & 2 & $1,1 \times 10^{4}$ & Neg. & Neg. & Neg. & $1 \times 10^{1}$ & $1,4 \times 10^{2}$ & Neg. & Neg. & Neg. \\
\hline & 3 & $6,4 \times 10^{3}$ & $2 \times 10^{3}$ & Neg. & Neg. & $2,5 \times 10^{2}$ & $6 \times 10^{1}$ & $6,4 \times 102$ & Neg. & $2 \times 10^{1}$ \\
\hline \multirow{3}{*}{$\begin{array}{l}\text { BP-Colônias } \\
\text { atípicas }\end{array}$} & 1 & $1,7 \times 10^{3}$ & ND & $4 \times 10^{1}$ & $5,7 \times 10^{2}$ & $3 \times 10^{3}$ & $2,4 \times 10^{3}$ & $3,3 \times 102$ & $1,0 \times 103$ & $2 \times 10^{5}$ \\
\hline & 2 & $1,8 \times 10^{5}$ & $3,5 \times 10^{3}$ & $1 \times 10^{3}$ & $9,1 \times 10^{2}$ & $2 \times 10^{3}$ & $2 \times 10^{3}$ & $2 \times 103$ & $1 \times 102$ & $2 \times 10^{3}$ \\
\hline & 3 & $1,1 \times 10^{5}$ & $2 \times 10^{3}$ & $1,4 \times 10^{3}$ & $4,6 \times 10^{3}$ & $2 \times 10^{3}$ & $2 \times 10^{3}$ & $2 \times 103$ & $1 \times 102$ & $5,3 \times 10^{2}$ \\
\hline \multirow{3}{*}{$\begin{array}{l}\text { Staphylococcus } \\
\text { aureus }\end{array}$} & 1 & $6,7 \times 10^{2}$ & ND & Neg. & Neg. & Neg. & Neg. & Neg. & Neg. & Neg. \\
\hline & 2 & $9,6 \times 10^{3}$ & Neg. & Neg. & Neg. & Neg. & $1,4 \times 10^{2}$ & Neg. & Neg. & Neg. \\
\hline & 3 & $3 \times 10^{3}$ & $1,6 \times 10^{3}$ & Neg. & Neg. & $9,5 \times 10^{2}$ & Neg. & $6,4 \times 102$ & Neg. & $2 \times 10^{1}$ \\
\hline
\end{tabular}


enterotoxinas [1, 16]. Especificamente, a avaliação de SCN isolados da pele, mucosas e leite de caprinos, resultou em $22 \%$ deles capazes de produzir enterotoxinas, sendo a tipo C, a mais encontrada [22]. Em outro estudo [6], não foi possível encontrar linhagens enterotoxigênicas entre isolados de SCN de leite caprino, porém essas linhagens puderam ser encontradas em queijos de leite caprino [23]. A partir disso, medidas que controlem as populações de SCN também devem ser consideradas importantes para a qualidade do produto final, uma vez que as enterotoxinas estafilocócicas são termo-estáveis, resistindo à pasteurização e às demais etapas do processamento e podendo chegar até o consumidor.

A quantificação de microorganismos mesófilos visa verificar a contaminação geral de um alimento e tem sido usada como indicador da qualidade higiênica dos alimentos, fornecendo também uma idéia sobre seu tempo útil de conservação [10]. Avaliando as contagens de mesófilos totais encontradas nos três lotes de queijo amostrados no presente estudo (Tabela 1) é possível acompanhar as variações ao longo das etapas de processamento. Partindo de contagens de $3,9 \times 10^{6}$ a $1,6 \times 10^{8} \mathrm{~mL}$ no leite recebido na plataforma, observa-se que a pasteurização foi capaz de reduzir a população de mesófilos presentes. A pasteurização foi, igualmente, capaz de eliminar a população de S. aureus e coliformes totais presentes no leite cru, demonstrando a importância dessa etapa, no controle de microorganismos patogênicos presentes na matéria-prima.

Entretanto, na etapa subseqüente do processamento, quando o leite era transferido com o auxílio de uma bomba aspirante, do pasteurizador para o tanque de coagulação, houve a introdução de grande número de mesófilos e coliformes totais no leite. Investigando a razão dessa recontaminação pós-pasteurização, observou-se que o equipamento utilizado nessa etapa era o mesmo usado na transferência do leite da plataforma para o pasteurizador. A prevenção do contato do leite cru com a matéria-prima pós-pasteurização, seja com os equipamentos ou por outra falha nas boas práticas de fabricação, é um dos principais cuidados que deve ser observado na indústria de laticínios com vistas à obtenção de um produto de qualidade higiênico-sanitária satisfatória [8].

Ao lado disso, a impossibilidade, por exigência do segmento de consumidores do mercado ecológico, da utilização de agentes químicos na sanificação de equipamentos, muito provavelmente agravou essa situação. Como alternativa ao uso desses produtos, todos os equipamentos eram escaldados com água a $100^{\circ} \mathrm{C}$ antes da utilização, enquanto as mangueiras ligadas à bomba aspirante, empregadas para a transferência do leite cru, eram lavadas com água fria antes de serem utilizadas para a transferência do leite pasteurizado.

Efetivamente, todos os suabes coletados na superfície dos equipamentos, após a aplicação do protocolo de sanificação adotado, resultaram na presença de incontáveis colônias bacterianas. De todos os equipamentos analisados (mangueira da bomba, tanque de coagulação, lira, forma, dessorador e superfície de salga), foi isolado Enterobacter sp., um dos gêneros que pertence ao grupo dos coliformes totais.

A água utilizada para a limpeza era proveniente de um poço artesiano, tendo sido encontradas contagens médias de 129,8 UFC/100 mL (Amplitude 11-500) de coliformes totais e $10 \mathrm{UFC} / 100 \mathrm{~mL}$ (Amplitude 4-17) de coliformes termotolerantes no período do estudo. Uma amostra de água a $100^{\circ} \mathrm{C}$, utilizada para a sanificação dos equipamentos, foi igualmente avaliada e não apresentou contagens de coliformes totais e termotolerantes. Entretanto, apesar de a água após a fervura não ter apresentado coliformes, aparentemente não foi capaz de eliminar populações bacterianas residuais, que permaneceram nos equipamentos em contato com o produto. Paralelamente, as mangueiras em contato com o leite eram higienizadas com a água sem aquecimento, que, além de diminuir ainda mais a eficiência do processo de eliminação da microbiota presente, foi mais um ponto de introdução de coliformes no produto.

Da mesma forma, à medida que foram adicionados os ingredientes (fermento, coalho) e que houve contato do produto com equipamentos e mãos dos manipuladores, observou-se um aumento das contagens de todos os indicadores avaliados.

Em relação aos estafilococos, esses podem ser introduzidos no alimento sob várias formas, entre elas o ato de o manipulador levar a mão à boca ou nariz [11]. Outra maneira é por meio de lesões estafilocócicas presentes na pele do funcionário que trabalha diretamente com o alimento [18]. No presente estudo, um dos funcionários do laticínio parece ter sido responsável pela introdução do microorganismo no produto durante o processo de embalagem do queijo. Apesar de os manipuladores não apresentarem isolamento de Staphylococcus aureus de suas fossas nasais, o microorganismo foi encontrado em um dos instrumentos utilizados e na mão de um dos manipuladores. Esse fato pode explicar o aparecimento de $S$. aureus na amostra coletada de queijo embalado, uma vez que o processo de embalagem era feito manualmente. Ao lado disso, durante a produção do terceiro lote de queijo detectou-se a presença de S. aureus no fermento, que pode ter sido responsável pela introdução da bactéria no produto.

Entretanto, em todos os lotes produzidos, o produto final manteve-se dentro dos parâmetros exigidos pela legislação para queijos tipo frescal [3]. Mesmo no lote onde houve contaminação por $S$. aureus, as contagens ficaram abaixo de $10^{3} \mathrm{UFC} / \mathrm{g}$, indicando que o produto estava apto para o consumo.

Comparando as contagens microbianas encontradas no produto final coletado na indústria (Tabela 1) e na chegada (dia 0) ao estabelecimento comercial (Tabela 2), observa-se que houve um aumento na contagem de todos os indicadores avaliados. Esse fato pode ter sido ocasionado por deficiências na refrigeração, principalmente durante a estocagem anterior à expedição do produto para o estabelecimento de comercialização, propiciando a multiplicação de mesófilos ao longo desse período. 
TABELA 2 - Contagens de mesófilos, coliformes totais e colônias atípicas em ágar Baird-Parker encontradas em amostras de queijo tipo frescal de leite de cabra coletadas em um estabelecimento comercial de Porto Alegre (RS)

\begin{tabular}{lcccc}
\hline \multirow{2}{*}{$\begin{array}{l}\text { Microorganismo } \\
\text { (UFC/g) }\end{array}$} & Lote & \multicolumn{3}{c}{ Tempo de prateleira (dias) } \\
\cline { 2 - 5 } & & $\mathbf{0}^{*}$ & $\mathbf{7}$ & $\mathbf{1 4}$ \\
\hline \multirow{3}{*}{ Mesófilos } & 1 & $6,23 \times 10^{9}$ & $9,16 \times 10^{6}$ & $3,5 \times 10^{3}$ \\
& 2 & $2,18 \times 10^{9}$ & $1,87 \times 10^{9}$ & $1,25 \times 10^{9}$ \\
& 3 & $1,21 \times 10^{9}$ & $1,05 \times 10^{6}$ & $8,9 \times 10^{3}$ \\
\hline \multirow{2}{*}{ Coliformes } & 1 & $\mathrm{ND}$ & $3 \times 10^{6}$ & $3 \times 10^{5}$ \\
totais & 2 & $3 \times 10^{6}$ & $3 \times 10^{6}$ & $1,5 \times 10^{6}$ \\
& 3 & $3 \times 10^{5}$ & $1 \times 10^{6}$ & $\mathrm{ND}$ \\
\hline \multirow{3}{*}{$\begin{array}{l}\text { BP-Colônias } \\
\text { atípicas** }\end{array}$} & 1 & $2 \times 10^{5}$ & $2 \times 10^{5}$ & $2 \times 10^{5}$ \\
& 2 & $2 \times 10^{5}$ & $2 \times 10^{5}$ & $2 \times 10^{5}$ \\
\hline *Amostra cota & 3 & $1,92 \times 10^{5}$ & $1,66 \times 10^{5}$ & $9,1 \times 10^{4}$ \\
\hline
\end{tabular}

*Amostra coletada no dia em que o produto chegou ao estabelecimento comercial. **Colônias atípicas em ágar Baird-Parker

Posteriormente, observou-se que a contagem de mesófilos diminuiu gradualmente nas amostras coletadas no estabelecimento comercial. Isso pode ter ocorrido em função de um aumento na acidificação [4] ou por ação do crescimento de microbiota secundária do queijo [15]. Ao lado disso, fatores como a embalagem a vácuo e o armazenamento sob refrigeração, também podem ter contribuído para a redução dos mesófilos. Entretanto, observa-se que não houve o mesmo efeito sobre a população de coliformes totais ou de bactérias formadoras de colônias atípicas no ágar Baird-Parker. Outros estudos demonstraram que alguns grupos de microorganismos como os micrococos e as leveduras podem ser introduzidos durante o processamento do queijo e, por apresentarem uma maior resistência à concentração de sal e à desidratação, persistem durante o processo de maturação e armazenamento. Mesmo bactérias patogênicas como Salmonella typhimurium e Yersinia enterocolitica puderam ser detectadas por até 42 dias em queijo de leite de cabra estocado sob refrigeração, indicando que algumas bactérias do grupo das mesófilas podem sobreviver sob essas condições.

A partir destas observações, devem ser adotadas pelo laticínio ações corretivas, como a utilização de equipamentos para uso exclusivo em área limpa; uso de água de boa qualidade; orientação dos manipuladores e responsáveis quanto às boas práticas de fabricação; e adoção de sanificante aceito pelo segmento de consumo de produtos naturais. Nesse sentido, estudos são necessários para testar substâncias sanificantes alternativas que possam ser adotadas pelo segmento de produtos ecológicos.

\section{4 - CONCLUSÃO}

A utilização de equipamentos com deficiente sanificação, e que haviam entrado em contato com o leite na plataforma, determinou a recontaminação pós-pasteuri- zação do produto. As falhas detectadas durante a fabricação do queijo não impediram que o mesmo estivesse dentro dos padrões exigidos pela legislação, entretanto encontrou-se elevada de contagem de mesófilos e coliformes totais no produto final, podendo comprometer a vida de prateleira do produto.

\section{5 - REFERÊNCIAS BIBLIOGRÁFICAS}

[1] BAUTISTA, L. GAYA, P.; MEDINA, M.; NUNES, M. A quantitative study of enterotoxin production by sheep milk staphylococci. Appl. Environ. Microbiol., v. 54, p. 4.799-4.806, 1988.

[2] BRASIL. Normatização Técnica L5.202. Companhia de Tecnologia de Saneamento Ambiental. Determinação do número mais provável de coliformes totais e fecais pela técnica de tubos múltiplos. São Paulo, 1978.

[3] BRASIL. Resolução RDC n ${ }^{\circ} 12$, de 2 de janeiro de 2001. Regulamento técnico sobre padrões microbiológicos para alimentos. Disponível em: http://www.anvisa.gov. br/legis/resol/12_01rdc.htm. Acesso em: 11 jun. 2001.

[4] CAMACHO, L.; SIERRA, C. Diagnostico sanitario y tecnologico del proceso artesanal del queso fresco de cabra en Chile. Archivos Latinoamericanos de Nutrición. Caracas, v. 38, n. 4, p. 935-945, 1988.

[5] CARDOSO, V.M.; SILVA, G.G.; CANO, V. Contagem de microorganismos. In: Análise Microbiológica de Alimentos. Rio de Janeiro, Quimitra, p. 20-27. 1985.

[6] DE BUYSER, M.L.; DILASSER, F.; HUMMEL, R.; BERGDOLL, M.S. Enterotoxin and toxic shock syndrome toxin-1 productio by Staphylococci isolated from goat's milk. Int. J. Food Microbiol., v. 5, p. 301-309, 1987.

[7] EUTHIER, S.M.F.; TRIGUEIRO, I.N.S.; RIVERA, F. Condições higiênico-sanitárias do queijo de leite de cabra "tipo coalho", artesanal elaborado no Curimataú paraibano. Ciência e Tecnologia de Alimentos, v. 18, n. 2, p. 162-164, 1998.

[8] FORSYTHE, S.J. Microbiologia da Segurança Alimentar. Porto Alegre, ArtMed Editora, 424 p., 2002.

[9] FOX, P. F. Cheese: chemistry, physics and microbiology. London, Chapman \& Hall, 463 p., 1993.

[10] FRANCO, B.D.G.M.; LANDGRAF, M. Microbiologia dos alimentos. São Paulo, Atheneu, 181 p. 1996.

[11] GONÇALVES, P.M.R. Toxinfecções alimentares: uma revisão. Higiene Alimentar. São Paulo, v. 12, n. 53, p. 38-43, 1998.

[12] INTERNATIONAL COMMISSION ON MICROBIOLOGICAL SPECIFICATIONS FOR FOODS (ICMSF). 1997. APPCC na Qualidade e Segurança Microbiológica de Alimentos. Varela, São Paulo. 377 p.

[13] JAY, J.M. Modern Food Microbiology, New York, Chapman \& Hall, 661 p., 1996.

[14] LANGE, C.C.; BRITO, J.R.F. Influência da qualidade do leite na manufatura e vida de prateleira dos produtos lácteos: papel das altas contagens microbianas. In: BRITO, J.R.F; PORTUGAL, J.A (Eds.) Diagnóstico da Gualidade do Leite, Impacto para a Indústria e a Questão dos Resíduos de Antibióticos, Embrapa, Juiz de Fora, p. 117-138. 2003.

[15] MANOLOPOULUS, E.; SARANTINOPOULUS, P.; ZOIDAN, E.; AKTYPIS, A.; MOSCHOPOULOU, E.; KANDARAKIS, I.G.; ANIFANTAKIS, E. Evolution of 
microbial populations during tradicitional feta cheese manufacture and ripening. Int.J.Food Microbiol., v. 82, p. 153-161, 2003.

[16] ORDEN, J.A; GOYACHE, J.; HERNANDEZ, J.; DOMENECH, A; SUAREZ, G.; GOMEZ-LUCIA, E. Production of staphylococcal enterotoxin and TSST 1 by coagulase negative staphylococi isolated from ruminant mastitis. J. Vet. Med. B., v. 39, p. 144-148, 1992.

[17] MACFADDIN, J.F. Biochemical tests for identification of medical bacteria. Philadelphia, Lippincott Williams \& Wilkins, 912 p., 2000.

[18] PEREIRA, M.L. et al. Estafilococos e alimentos: possibilidades de disseminação através do portador humano e animal. Higiene Alimentar. São Paulo, v. 13, n. 66/67, p. 48-55, 1999.

[19] SÁ, FV. A Cabra. Lisboa, Livraria Clássica, 63 p., 1978.
[20] SCHOLZ, W. Elaboración de quesos de oveja y de cabra. Zaragoza: Acribia, 145 p., 1997.

[21] SILVA, N.; JUNQUEIRA, V.C.A.; SILVEIRA, N.F.A. Manual de métodos de análise microbiológica de alimentos. São Paulo, Varella, 295 p., 1997.

[22] VALLE, J.; GOMEZ-LUCIA, E.; PIRIZ, S.; GOYACHE, J.; ORDEN, J.A; VADILLO, S. Enterotoxin production by staphylococci isolated from healthy goats. Appl. Environ. Microbiol., v. 56, p. 1.323-1.326, 1990.

[23] VERNOZY-ROZAND, C.; MAZUY, C.; PREVOST, G.; LAPEYRE, C.; BES, M.; BRUN, Y.; FLEURETTE, J. Enterotoxin production by coagulase-negative staphylococci isolated from goat's milk and cheese. Int. J. Food Microbiol., v. 30, p. 271-280, 1996.

[24] ZOTTOLA, E.A; SMITH, L.B. Pathogens in cheese. J. Food Microbiol., v. 8. P. 171-182, 1991. 